Check for updates

Cite this: Chem. Sci., 2019, 10, 2006

๑ All publication charges for this article have been paid for by the Royal Society of Chemistry

\title{
Waterproof architectures through subcomponent self-assembly $\dagger$
}

\author{
Edmundo G. Percástegui, (D) Jesús Mosquera, Tanya K. Ronson, (D) Alex J. Plajer, \\ Marion Kieffer (D) and Jonathan R. Nitschke (D)*
}

\begin{abstract}
Metal-organic containers are readily prepared through self-assembly, but achieving solubility and stability in water remains challenging due to ligand insolubility and the reversible nature of the self-assembly process. Here we have developed conditions for preparing a broad range of architectures that are both soluble and kinetically stable in water through metal(॥)-templated ( $\mathrm{M}^{\prime \prime}=\mathrm{Co}^{\prime \prime}, \mathrm{Ni}{ }^{\prime \prime}, \mathrm{Zn}^{\prime \prime}, \mathrm{Cd}^{\prime \prime}$ ) subcomponent self-assembly. Although these structures are composed of hydrophobic and poorlysoluble subcomponents, sulfate counterions render them water-soluble, and they remain intact indefinitely in aqueous solution. Two strategies are presented. Firstly, stability increased with metalligand bond strength, maximising when $\mathrm{Ni}^{\prime \prime}$ was used as a template. Architectures that disassembled when $\mathrm{CO}^{\prime \prime}, \mathrm{Zn}^{\prime \prime}$ and $\mathrm{Cd}^{\prime \prime}$ templates were employed could be directly prepared from $\mathrm{NiSO}_{4}$ in water. Secondly, a higher density of connections between metals and ligands within a structure, considering both ligand topicity and degree of metal chelation, led to increased stability. When tritopic amines were used to build highly chelating ligands around $\mathrm{Zn}^{\prime \prime}$ and $\mathrm{Cd}^{\prime \prime}$ templates, cryptate-like water-soluble structures were formed using these labile ions. Our synthetic platform provides a unified understanding of the elements of aqueous stability, allowing predictions of the stability of metal-organic cages that have not yet been prepared.
\end{abstract}

Received 14th November 2018

Accepted 12th December 2018

DOI: $10.1039 / \mathrm{c} 8 \mathrm{sc} 05085 f$

rsc.li/chemical-science that hold these structures together. The assembly of architectures that hold together robustly in water has thus required the use of more costly second ${ }^{-4 a, 8,11}$ and third-row metals, ${ }^{12}$ which are kinetically more inert. This approach may lead to formation of kinetically trapped intermediates, ${ }^{12 a, 13}$ which has in turn led to the development of metal-exchange or redox modifications on preformed assemblies in order to kinetically "lock" a structure and prevent its disassembly. ${ }^{14}$

The subcomponent self-assembly method has been widely used by others ${ }^{15}$ and us $^{16}$ to construct metal-organic architectures through the synergistic formation of dynamic covalent $(\mathrm{C}=\mathrm{N})$ imine $^{4 b, 17}$ and coordinative $\mathrm{N} \rightarrow$ metal ion linkages. The formation of cages that are soluble and stable in water via subcomponent self-assembly has been possible only when sufficiently water-soluble subcomponents are used. ${ }^{2 a, 9 a, 10 a}$ Although the exchange of trifluoromethanesulfonate ( $\left.\mathrm{OTf}^{-}\right)$for sulfate anions $\left(\mathrm{SO}_{4}{ }^{2-}\right)$ on preformed $\mathrm{Fe}^{\mathrm{II}}$ cages constructed from water-insoluble subcomponents provided a route to water solubility in certain cases, ${ }^{18}$ many cages thus prepared disassembled at room temperature. When subcomponents lack sufficient water solubility, the trace amounts of disassembled precursors present at equilibrium can reach saturation and precipitate, thus resulting in the observed disassembly. As a result, the low water solubility of the more accessible hydrophobic ligands appears at first glance to preclude their integration into water-soluble cages. 
The strategies developed herein complement past methods, allowing for many of the limitations discussed above to be overcome. Specific combinations of water-insoluble subcomponents with salts of nickel(II), cobalt(II), zinc(II), and cadmiu$\mathrm{m}$ (II) resulted in the facile assembly of kinetically robust watersoluble structures ranging from face-capped $\mathrm{M}_{8} \mathrm{~L}_{6}$ cubes and $\mathrm{M}_{4} \mathrm{~L}_{4}$ tetrahedra, to edge-linked $\mathrm{M}_{4} \mathrm{~L}_{6}$ tetrahedra, and $\mathrm{M}_{2} \mathrm{~L}_{3}$ triple helicates.

The use of sulfate as the counterion was essential to bring about water solubility, and it was introduced either by direct assembly from $\mathrm{M}^{\mathrm{II}} \mathrm{SO}_{4}$ or via anion-exchange from acetonitrilesoluble structures. Stability in aqueous media was achieved using two distinct strategies. Firstly, we took advantage of the diverse degree of kinetic inertness of metal ions with stability order of $\mathrm{Ni}^{\mathrm{II}}>\mathrm{Fe}^{\mathrm{II}}>\mathrm{Co}^{\mathrm{II}}>\mathrm{Zn}^{\mathrm{II}}>\mathrm{Cd}^{\mathrm{II}} \cdot{ }^{19}$ Using $\mathrm{Ni}^{\mathrm{II}}$ as a template maximised the strength of metal-ligand bonding, thus stabilising the product complexes to hydrolysis and decomposition. The second strategy enhanced the binding cooperativity ${ }^{20}$ around metal templates through (a) the use of subcomponents of increasing topicity (ability to bridge between varying numbers of metal ions), and (b) the augmentation of chelate effects. Hence, subcomponents that form tetratopic ligands, able to bridge four metal ions, were observed to form the most stable cages, followed by tri- and ditopic ones. $\mathrm{Zn}^{\mathrm{II}}$ and $\mathrm{Cd}^{\mathrm{II}}$ ions did not bind strongly enough, even to tetratopic ligands, to prevent aqueous disassembly. Water-stable cages containing these metal ions could be constructed, however, by incorporating tritopic chelating amines to cap the vertices of $\mathrm{Zn}^{\mathrm{II}}$ - and $\mathrm{Cd}^{\mathrm{II}}$-based assemblies. The more densely-connected structures thus obtained were stabilised by extensive chelate effects, ${ }^{20}$ and represent the first water-soluble subcomponent self-assembled structures containing these labile $\mathrm{Zn}^{\mathrm{II}}$ and $\mathrm{Cd}^{\mathrm{II}}$ cations, complimenting rare examples of aqueous coordination assemblies that incorporate these metals. ${ }^{21}$

\section{Results and discussion}

Self-assembly reactions to form water-soluble polyhedra as sulfate salts were attempted using subcomponents A-E (Scheme 1) with divalent metal ions $\left(\mathrm{M}^{\mathrm{II}}=\mathrm{Co}^{\mathrm{II}}, \mathrm{Ni}^{\mathrm{II}}, \mathrm{Zn}^{\mathrm{II}}, \mathrm{Cd}^{\mathrm{II}}\right)$ as detailed below. We chose these subcomponents to gauge the role of different metal ions on cage stability through comparison with their $\mathrm{Fe}^{\mathrm{II}}$ analogues. ${ }^{18}$

\section{Cobalt(II) architectures}

The Co ${ }^{\text {II }}$ capsules shown in Scheme 1 were prepared from subcomponents $\mathbf{A}-\mathbf{E}$ in acetonitrile and subjected to anion metathesis. The formation of these acetonitrile-soluble cages was sensitive to the identity of the counterion, and none could be formed as clean products directly from $\mathrm{CoSO}_{4}$ (ESI Section $2 \dagger)$.

The reaction between fourfold-symmetric zinc porphyrin A, 2-formylpyridine, and cobalt(II) trifluoromethanesulfonate in DMF produced the previously unknown cube Co-1.OTf, as revealed by electrospray mass spectrometry (ESI-MS). Addition of tetrabutylammonium (TBA) sulfate to an MeCN solution of
Co-1.OTf led to precipitation of $\mathbf{C o - 1} \cdot \mathbf{S O}_{4}$ as a magenta solid that was soluble in water (Fig. S1 and S2 $\dagger$ ). The wide-sweep ${ }^{1} \mathrm{H}$ NMR spectrum in $\mathrm{D}_{2} \mathrm{O}$ was consistent with the $O$-symmetric structure previously observed for the $\mathrm{Fe}^{\mathrm{II}}$ analogue. ${ }^{18,22}$ Dispersion of eleven proton signals over the range 245.2 to $-63.9 \mathrm{ppm}$ confirmed the presence of paramagnetic $\mathrm{Co}^{\mathrm{II}}$ ions at the cage vertices. No decomposition of cage Co-1. $\mathbf{S O}_{4}$ in $\mathrm{D}_{2} \mathrm{O}(50.0 \mu \mathrm{M}$ and $500 \mu \mathrm{M}$ ) was detected by NMR spectroscopy after 3 months at $25{ }^{\circ} \mathrm{C}$. In contrast, heating these solutions to $50{ }^{\circ} \mathrm{C}$ led to complete cube decomposition within $8 \mathrm{~h}$ as evidenced by precipitation of blue porphyrin $\mathbf{A}$ and disappearance of the signals in the ${ }^{1} \mathrm{H}$ NMR spectrum.

The water stability of $\mathbf{C o - 1} \cdot \mathbf{S O}_{\mathbf{4}}$ allowed reversibility of the anion exchange process. Addition of LiOTf to a $\mathrm{D}_{2} \mathrm{O}$ solution of Co-1. $\mathrm{SO}_{4}$ produced a purple precipitate that was soluble in acetonitrile. NMR and ESI-MS analyses matched those of the initial Co-1. OTf product (Fig. S3 and S4 $\dagger$ ). The complete Co1.OTf $\rightarrow$ Co-1. $\mathbf{S O}_{4} \rightarrow$ Co-1.OTf anion exchange cycle was carried out twice with $90-94 \%$ recovery by weight per cycle.

Slow diffusion of benzene into an acetonitrile solution of Co1. OTf afforded brown crystals of the complex; Co-1 crystallised in the tetragonal space group P4/n (Fig. 1). All of the Co ${ }^{\mathrm{II}}$ centres adopt the same $\Delta$ or $\Lambda$ configuration, and both enantiomers are present in the crystal lattice. The internal cavity volume of 1331 $\AA^{3}$ (ESI Section $7 \dagger$ ) is similar to the previously reported $\mathrm{Fe}^{\mathrm{II}}$ analogue $\left(1340 \AA^{3}\right) .{ }^{22}$ In the solid state this cavity is occupied by disordered acetonitrile and benzene solvent molecules; we infer that solvent molecules are also likely to occupy the cavity in solution.

The reaction of trianiline $\mathbf{B}$ with 2 -formylpyridine and cobalt(II) sulfate yielded a crude mixture containing the target water-soluble $\mathrm{Co}_{4} \mathrm{II}_{4}$ tetrahedron as the major product and a $\mathrm{Co}_{2}^{\mathrm{II}} \mathrm{L}_{3}$ helicate (detected by ESI-MS and NMR spectroscopy) analogous to previously-observed $\mathrm{Fe}^{\mathrm{II}}$ congeners; ${ }^{23}$ these products were not amenable to separation. Conversely, treatment of B with 2-formylpyridine and cobalt(II) bis(trifluoromethanesulfonyl)imide (triflimide, $\mathrm{NTf}_{2}$ ) in $\mathrm{CH}_{3} \mathrm{CN}$ produced cleanly the face-capped $\mathrm{Co}_{4}^{\mathrm{II}} \mathrm{L}_{4}$ tetrahedral capsule Co$\mathbf{2} \cdot \mathbf{N T f}_{\mathbf{2}}$. This cage incorporates four $\mathrm{Co}^{\mathrm{II}}$ centres bridged by four threefold-symmetric ligands (L) resulting from the condensation of aniline $\mathbf{B}$ with 3 equivalents of 2 -formylpyridine.

Treatment of $\mathbf{C o - 2} \cdot \mathbf{N T f}_{2}$ with $\mathrm{TBA}_{2} \mathrm{SO}_{4}$ in acetonitrile yielded the water-soluble $\mathbf{C o - 2} \cdot \mathbf{S O}_{4}$ salt as a dark orange precipitate. The wide-sweep ${ }^{1} \mathrm{H}$ NMR spectrum in $\mathrm{D}_{2} \mathrm{O}$ revealed a highly symmetric product; eight proton signals for the ligand were distributed over the range of 241.2 to -19.6 ppm (Fig. S5 $\dagger$ ). ESIMS in aqueous solution further confirmed the $\mathrm{Co}_{4} \mathrm{LI}_{4}$ composition of $\mathbf{C o - 2} \cdot \mathbf{S O}_{4}$ (Fig. S6 $\mathbf{S}^{\dagger}$ ). No decomposition was observed for aqueous solutions $(250-750 \mu \mathrm{M})$ of $\mathbf{C o - 2} \cdot \mathbf{S O}_{4}$ after two months at $25{ }^{\circ} \mathrm{C}$; on the contrary and regardless of the concentration, complete decomposition within $6 \mathrm{~h}$ was observed when these solutions were heated to $50{ }^{\circ} \mathrm{C}$, indicating kinetic but not thermodynamic stability.

The addition of $\operatorname{LiNTf}_{2}$ to an aqueous solution of $\mathbf{C o - 2} \cdot \mathbf{S O}_{4}$ resulted in precipitation of the $\mathbf{C o - 2} \cdot \mathbf{N T f}_{2}$ derivative, as confirmed by NMR spectroscopy and ESI-MS (Fig. S7 and S8 $\dagger$ ). Further addition of $\mathrm{TBA}_{2} \mathrm{SO}_{4}$ to this acetonitrile solution of Co- 

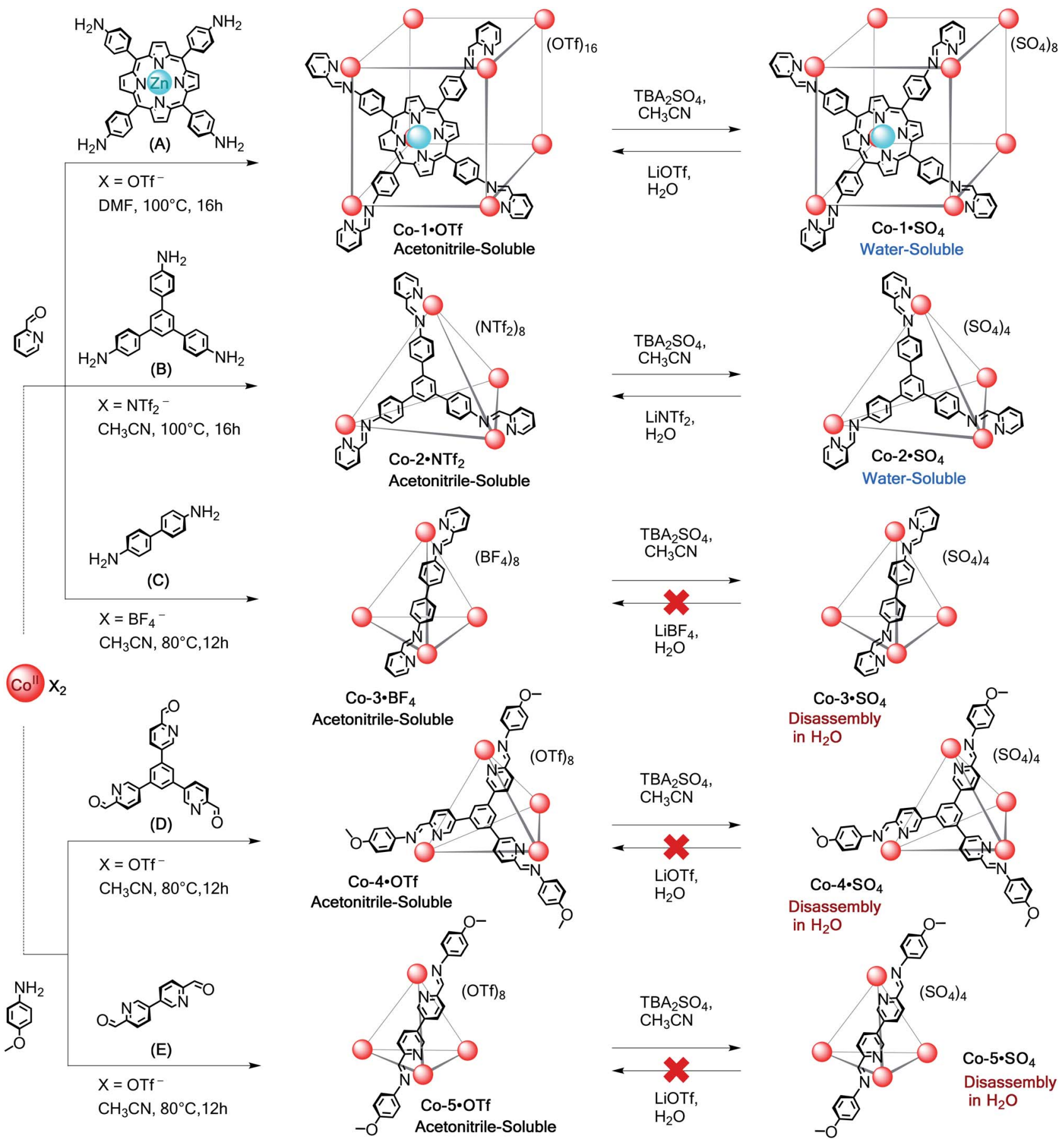

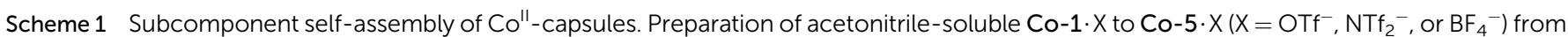
subcomponents $\mathrm{A}-\mathrm{E}$ and their anion exchange sequences.

$\mathbf{2} \cdot \mathbf{N T f}_{2}$ induced precipitation of $\mathbf{C o - 2} \cdot \mathbf{S O}_{4}$. The complete $\mathbf{C o}-$ $\mathbf{2} \cdot \mathbf{N T f}_{2} \rightarrow \mathbf{C o}-\mathbf{2} \cdot \mathbf{S O}_{\mathbf{4}} \rightarrow \mathbf{C o}-\mathbf{2} \cdot \mathbf{N T f} \mathbf{2}_{2}$ anion exchange cycle was carried out twice, with $90-95 \%$ recovery by weight per cycle.

Subcomponent self-assembly of benzidine $\mathbf{C}$ with 2-formylpyridine and $\mathrm{Co}\left(\mathrm{BF}_{4}\right)_{2}$ afforded the previously-unreported tetrahedral cage $\mathbf{C o - 3} \cdot \mathbf{B F}_{\mathbf{4}}$ as the single product (Fig. S9 and $\left.\mathrm{S} 10^{\dagger}\right)$; the ESI-MS showed only peaks corresponding to the $\mathrm{Co}_{4}^{\mathrm{II}} \mathrm{L}_{6}$ complex. The analogous $\mathrm{Fe}_{4}^{\mathrm{II}} \mathrm{L}_{6}$ cage, incorporating aniline $\mathbf{C}$, exists as a system of interconverting diastereomers in solution, ${ }^{24}$ where $\mathrm{BF}_{4}{ }^{-}$led to the $T$-symmetric diastereomer as the main species. This anion gave a similar diastereoselectivity in the present case. The wide-sweep ${ }^{1} \mathrm{H}$ NMR spectrum in $\mathrm{CD}_{3} \mathrm{CN}$ contained clusters of peaks consistent with a mixture of homochiral $T(\Delta \Delta \Delta \Delta / \Lambda \Lambda \Lambda \Lambda)$, heterochiral $C_{3}(\Delta \Delta \Delta \Lambda / \Lambda \Lambda \Lambda \Delta)$, and achiral $S_{4}(\Delta \Delta \Lambda \Lambda)$ diastereomers as previously observed for the $\mathrm{Fe}_{4} \mathrm{II}_{6}$ cage system. ${ }^{24}$ We could clearly distinguish a set of seven major peaks, consistent with the presence of the 


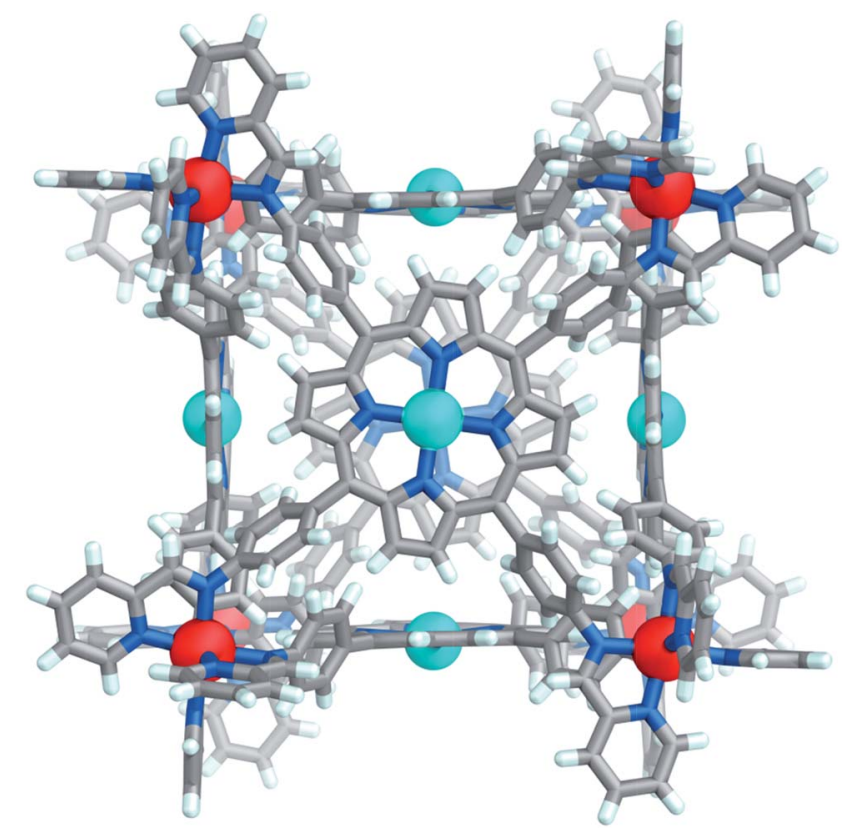

Fig. 1 Crystal structure of cube Co-1.OTf. Counterions, solvents and disorder are omitted for clarity. Co" and $\mathrm{Zn}^{\text {"l }}$ centers are coloured dark orange and cyan, respectively.

corresponding $T$-symmetric diastereomer as the predominant species.

Anion exchange of OTf $f^{-}$for $\mathrm{SO}_{4}{ }^{2-}$ induced precipitation of a pale orange solid, which dissolved in $\mathrm{D}_{2} \mathrm{O}$. However, disassembly took place within minutes, thus hindering any attempt to regenerate the initial $\mathbf{C o - 3} \cdot \mathbf{B F}_{\mathbf{4}}$ cage. We attribute the marked difference in stability between capsules $\mathbf{C o -} \cdot \mathbf{2} \cdot \mathbf{S O}_{4}$ and $\mathbf{C o -} \cdot \mathbf{3} \cdot \mathbf{S O}_{4}$ to the more robust framework that resulted from self-assembly of the tritopic aniline $\mathbf{B}$.

Next we prepared the new cage Co-4·OTf as well as Co-5·OTf, the framework of which was previously reported incorporating toluidine, ${ }^{25}$ from tritopic and ditopic aldehydes $\mathbf{D}$ and $\mathbf{E}$, respectively, anisidine, and $\mathrm{Co}(\mathrm{OTf})_{2}$. Their identities were confirmed through NMR and ESI-MS analyses. The addition of $\mathrm{TBA}_{2} \mathrm{SO}_{4}$ to MeCN solutions of both cages generated orange precipitates that we infer to consist of the corresponding sulfate salts. However, the dissolution of these precipitates in $\mathrm{D}_{2} \mathrm{O}$ led to decomposition as evidenced by precipitation of subcomponents D and E. NMR analysis of a $\mathrm{D}_{2} \mathrm{O}$ solution of $\mathbf{C o}-\mathbf{4} \cdot \mathbf{S O}_{4}$ showed that $c a$. $80 \%$ was hydrolysed after $1 \mathrm{~h}$ at room temperature; in contrast, it was not possible to observe any cage peaks when the precipitate of $\mathbf{C o - 5} \cdot \mathbf{S O}_{\mathbf{4}}$ was dissolved in $\mathrm{D}_{2} \mathrm{O}$, due to its more rapid disassembly.

\section{Nickel(II) architectures}

Although many coordination cages incorporating $\mathrm{Fe}^{\mathrm{II}}$ (ref. $15 a-e, 22-24$ and 26) and $\mathrm{Co}^{\mathrm{II}}$ (ref. $3 a, 5 a, 15 f, 25$ and 27) have been reported, far fewer have used $\mathrm{Ni}^{\mathrm{II}}{ }^{28}$ despite the stronger coordination bonds this metal ion forms with nitrogen ligands. ${ }^{29}$ Our own enquiries into $\mathrm{Ni}^{\mathrm{II}}$-based structures have been limited by difficulties in obtaining structural information in solution; ${ }^{28 b-c ~}{ }^{1} \mathrm{H}$ NMR signals of octahedral $\mathrm{Ni}^{\mathrm{II}}$ complexes are in many cases unresolvably broad due to unfavourable relaxivity. ${ }^{30}$

The series of new $\mathrm{Ni}^{\mathrm{II}}$ polyhedra (Schemes 2 and 3) reported herein were characterised using ESI-MS and X-ray crystallography in some cases. To supply further NMR structural evidence, ${ }^{19} \mathrm{~F}$ NMR spectroscopy was employed to verify the binding of fluorinated guests within the cage cavities (Scheme 2 and ESI Section 3.6†). These guests were observed to bind only in $\mathrm{D}_{2} \mathrm{O}$, suggesting that the hydrophobic effect is essential for their encapsulation in water. ${ }^{5}$ Unlike the iron(II) ${ }^{18}$ and cobalt(II) systems assembled from subcomponents $\mathbf{A}-\mathbf{E}$, it was possible to obtain water-soluble structures from direct assembly with $\mathrm{NiSO}_{4}$ in certain cases. The stronger coordination bonds of the $\mathrm{Ni}^{\mathrm{II}}$ structures led to greater stability in aqueous solution, as detailed below.

Reaction of tetratopic aniline A with 2-formylpyridine and $\mathrm{Ni}(\mathrm{OTf})_{2}$ in DMF afforded the cube Ni-1.OTf. Exchange of triflate for sulfate resulted in precipitation of the water-soluble Ni$\mathbf{1} \cdot \mathrm{SO}_{\mathbf{4}}$ cage as a red-brown solid; ESI-MS analysis of an aqueous solution of this precipitate corresponded to a $\mathrm{Ni}_{8}^{\mathrm{II}} \mathrm{L}_{6}$ cubic framework (Fig. S14 $\dagger$ ). Aqueous solutions of Ni-1/ $\mathbf{S O}_{4}$ developed no precipitate after 3 months at room temperature; ESIMS spectra (recorded periodically) of these solutions showed the presence of the cubic cage. Conversely, Ni-1. $\mathbf{S O} \mathbf{O}_{4}$ decomposed within $16 \mathrm{~h}$ at $85^{\circ} \mathrm{C}$, as evidenced by precipitation of the water-insoluble $\mathrm{Zn}$-porphyrin A. Addition of LiOTf to a $\mathrm{H}_{2} \mathrm{O}$ solution of Ni-1. $\mathbf{S O}_{4}$ resulted in regeneration of Ni-1. OTf, as confirmed by ESI-MS in MeCN. Slow diffusion of benzene into this solution gave dark green-brown crystals of Ni-1.OTf (Fig. 2a), which was isomorphous to cube Co-1.OTf. As in the case of Ni-1 - OTf, the internal cavity, which has a volume of 1324 $\AA^{3}$ (ESI Section 7†), is occupied by disordered solvent molecules.

In contrast to our observations for iron(II) ${ }^{18}$ and cobalt(II), triand ditopic anilines $\mathbf{B}$ and $\mathbf{C}$ reacted readily with $\mathrm{NiSO}_{4}$ to form the $\mathbf{N i - 2} \cdot \mathbf{S O}_{4}$ and $\mathbf{N i}-\mathbf{3} \cdot \mathbf{S O}_{4}$ tetrahedra in a $1: 1 \mathrm{CH}_{3} \mathrm{CN}: \mathrm{H}_{2} \mathrm{O}$ as identified by ESI-MS in $\mathrm{H}_{2} \mathrm{O}$ (Fig. $\mathrm{S} 16$ and $\mathrm{S} 18 \dagger$ ). Addition of LiOTf to cages Ni-2$\cdot \mathbf{S O}_{4}$ and $\mathbf{N i - 3} \cdot \mathbf{S O}_{4}$ in water resulted in the precipitation of the corresponding Ni-2.OTf and Ni-3.OTf capsules, as verified by ESI-MS analyses in MeCN (Fig. S17 and S19†).

Single-crystal X-ray diffraction on a yellow crystal obtained from slow diffusion of ${ }^{\mathrm{i}} \mathrm{Pr}_{2} \mathrm{O}$ into an $\mathrm{MeCN}$ solution of $\mathrm{Ni}-3$ in the presence of excess $\mathrm{BF}_{4}{ }^{-}$confirmed its $\mathrm{Ni}_{4}{ }_{4}^{\mathrm{II}} \mathrm{L}_{6}$ composition (Fig. 2b). Cage Ni-3.OTf crystallised in the monoclinic space group $C 2 / c$. The architecture is tetrahedral with noncrystallographic $T$ point symmetry, with both enantiomers present in the unit cell. $\mathrm{A} \mathrm{BF}_{4}{ }^{-}$guest anion was bound in the capsule cavity, benefiting from stabilising $\mathrm{CH}^{\cdots} \cdots \mathrm{F}$ non-classical hydrogen-bonding interactions. ${ }^{31}$ Cages Ni-2.OTf and Ni3. OTf were converted back into $\mathbf{N i}-2 \cdot \mathbf{S O}_{4}$ and $\mathbf{N i - 3} \cdot \mathbf{S O}_{4}$ following treatment in $\mathrm{MeCN}$ with $\mathrm{TBA}_{2} \mathrm{SO}_{4}$. The anion exchange sequence was carried out twice with $\pm 95 \%$ cage recovery.

To verify the encapsulation abilities of these complexes, we treated them with fluorobenzene, 1,3,5-trifluorobenzene, and hexafluorobenzene as prospective guests. The binding of each 


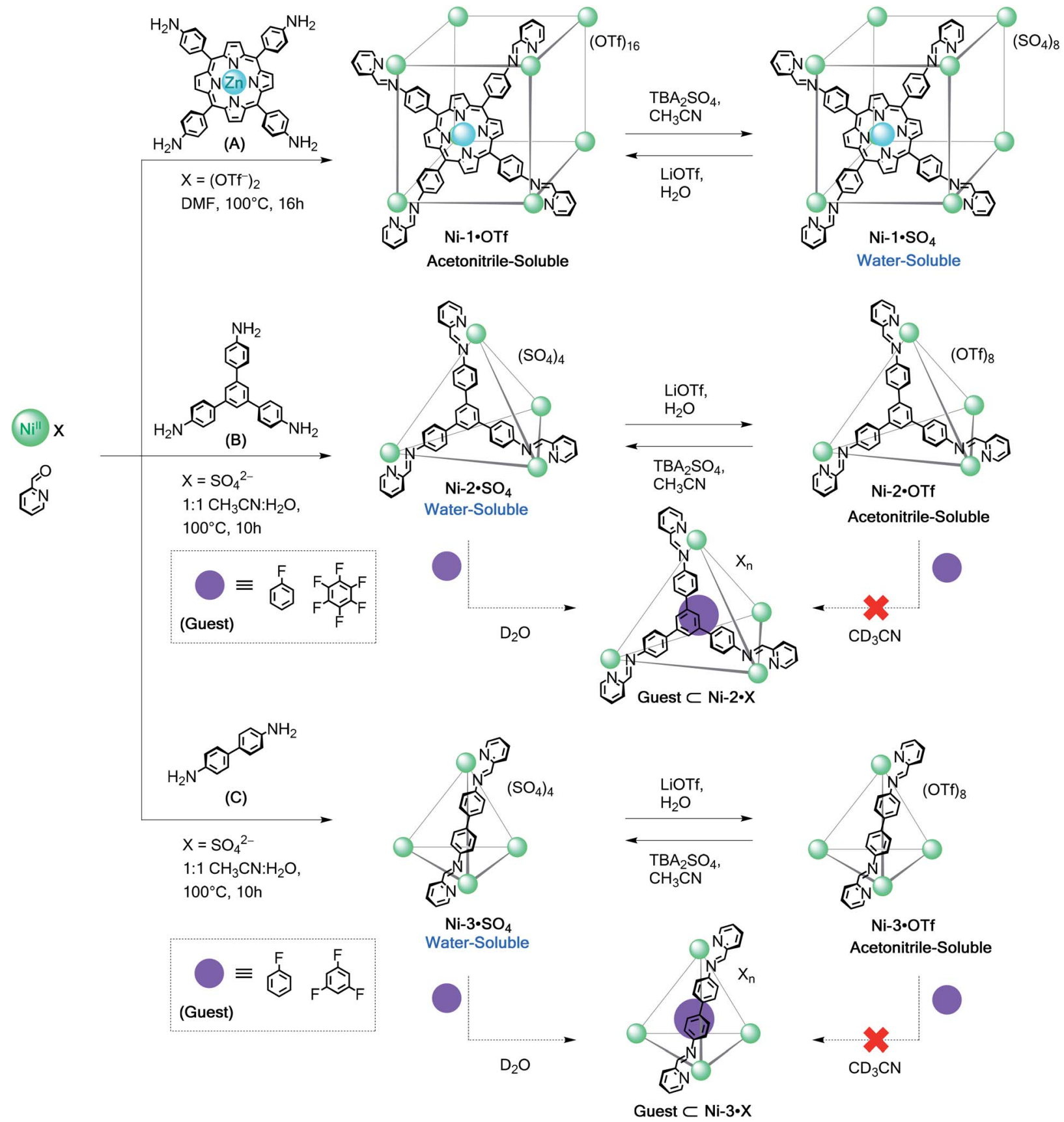

Scheme 2 Subcomponent self-assembly of water-soluble $\mathrm{Ni}-1 \cdot \mathrm{SO}_{4}$ to $\mathrm{Ni}-3 \cdot \mathrm{SO}_{4}$ cages from anilines $\mathrm{A}-\mathrm{C}$, their reversible anion-exchange sequences and encapsulation of selected fluorinated guests.

was followed by ${ }^{19} \mathrm{~F}$ NMR spectroscopy. No encapsulation was inferred to have taken place with Ni-2.OTf and Ni-3.OTf in $\mathrm{CD}_{3} \mathrm{CN}$. Only one ${ }^{19} \mathrm{~F}$ NMR signal for the prospective guest was observed in each case at the same chemical shift as in the absence of the host. Conversely, all of these guests were inferred to bind within $\mathbf{N i - 2} \cdot \mathbf{S O}_{4}$ and $\mathbf{N i - 3} \cdot \mathbf{S O}_{4}$ in $\mathrm{D}_{2} \mathrm{O}$ because new peaks were observed for the free and encapsulated guests. The peaks for the free fluorinated molecules, which were added in excess, progressively disappeared likely due to separation and evaporation from the aqueous solution given their poor solubility in water. As a result, only the peaks of the host-guest complexes persisted in the ${ }^{19}$ F NMR spectra over time (Fig. S23-S25 $\dagger$ ). This difference in binding parallels that observed for related systems using these solvents, and suggests that the hydrophobic effect may be essential for encapsulation in water. ${ }^{5,18}$

The reaction of tritopic aldehyde $\mathbf{D}$ with $\mathrm{NiSO}_{4}$ and anisidine yielded Ni-4 $\cdot \mathbf{S O}_{4}$ in aqueous solution (Scheme 3 ), as revealed by ESI-MS (Fig. S20†). This $\mathrm{Ni}_{4}^{\mathrm{II}} \mathrm{L}_{4}$ framework also remained intact following anion exchanges. The addition of LiOTf produced the water-insoluble congener as characterised by ESI-MS (Fig. S21†). This sequence could be reversed to reform the parent watersoluble sulfate cage upon treatment with $\mathrm{TBA}_{2} \mathrm{SO}_{4}$. Similar to 


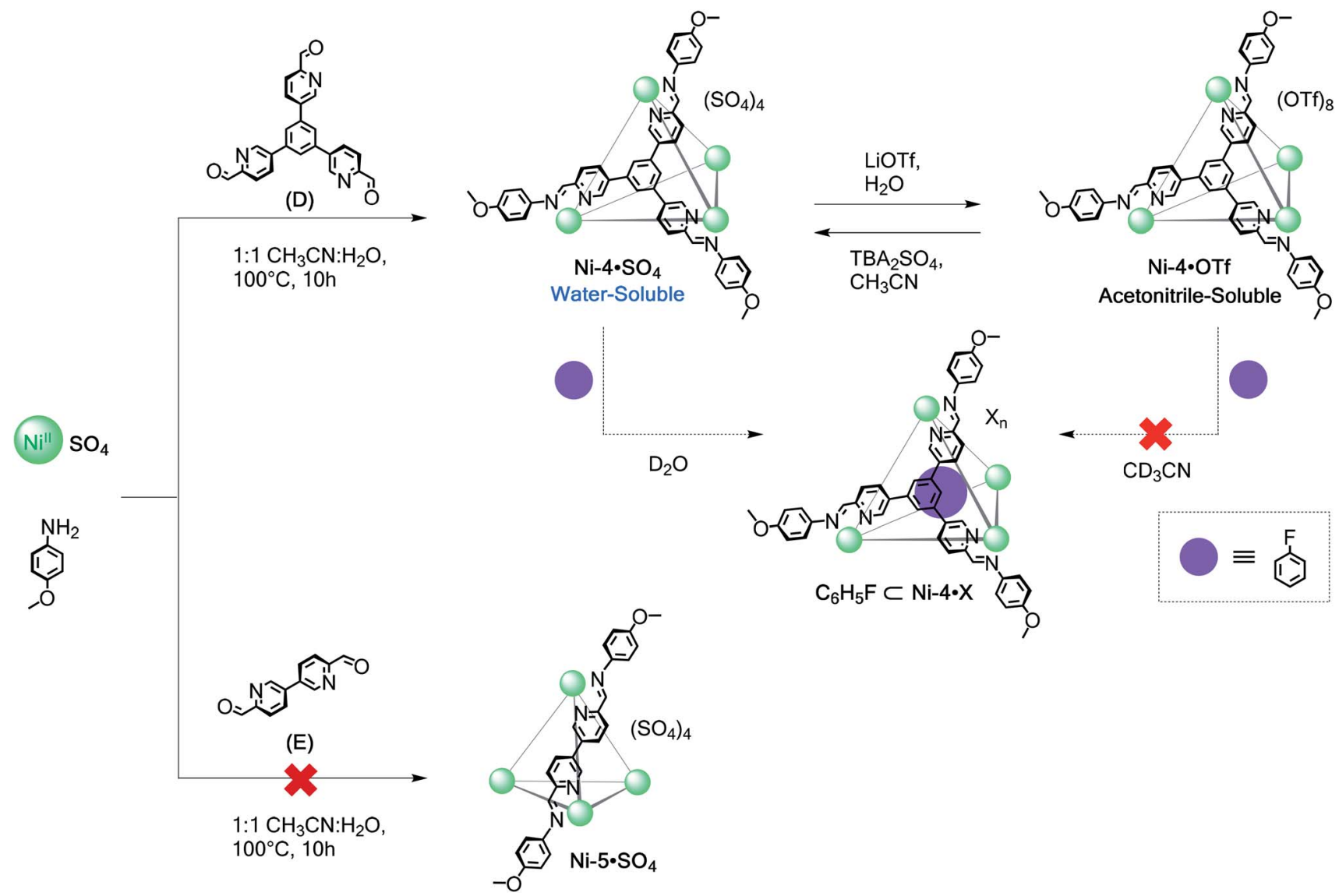

Scheme 3 Self-assembly reactions of aldehydes D and E with nickel(॥) salts.
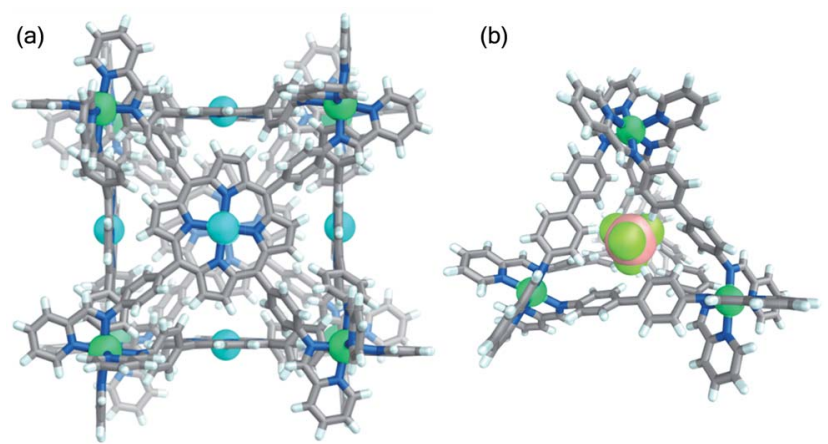

Fig. 2 Crystal structures of (a) cube $\mathrm{Ni}-1$ and (b) tetrahedron $\mathrm{Ni}-3$ viewed through an open face and showing the included $\mathrm{BF}_{4}{ }^{-}$anion. Counterions, solvents and disorder are omitted for clarity. Ni, Zn, F, and $B$ atoms are coloured green, cyan, pale green and pink, respectively.

capsules $\mathbf{N i - 2} \cdot \mathbf{S O}_{4}$ and $\mathbf{N i - 3} \cdot \mathbf{S O}_{4}$, tetrahedron $\mathbf{N i - 4} \cdot \mathbf{S O}_{4}$ also bound fluorobenzene in $\mathrm{D}_{2} \mathrm{O}$, as indicated by the presence of signals corresponding to the free and encapsulated guest in the ${ }^{19}$ F NMR spectrum (Fig. S24 and S25†).

Conversely, the reaction of ditopic aldehyde $\mathbf{E}$ with $\mathrm{NiSO}_{4}$ did not afford the sulfate salt of the cage, instead yielding only intractable products. As previously observed, ${ }^{28 c} \mathbf{E}$ reacts with $\mathrm{Ni}(\mathrm{OTf})_{2}$ to form a mixture of assemblies. When treated with
$\mathrm{TBA}_{2} \mathrm{SO}_{4}$ in $\mathrm{MeCN}$, this mixture gave species that were initially soluble in water, but which decomposed by precipitation within minutes.

\section{Self-assembly with labile metal ions: zinc(II) and cadmium(II)} architectures

To further extend the scope and value of the subcomponent selfassembly method in water, we have investigated the construction of water-soluble architectures using $\mathrm{Zn}^{\mathrm{II}}$ and $\mathrm{Cd}^{\mathrm{II}}$, which are much more labile $\left(K_{\mathrm{H}_{2} \mathrm{O}}=10^{7}\right.$ and $10^{8} \mathrm{~s}^{-1}$, respectively) than their transition metal ion congeners. ${ }^{19}$ As with $\mathrm{Fe}^{\mathrm{II}}$, $\mathrm{Co}^{\mathrm{II}}$, and $\mathrm{Ni}^{\mathrm{II}}$, subcomponents $\mathbf{A}-\mathbf{E}$ formed acetonitrile-soluble capsules with the more labile ions $\mathrm{Zn}^{\mathrm{II}}$ and $\mathrm{Cd}^{\mathrm{II}}$ from the corresponding triflate salts; Scheme 4 shows these reactions using $\mathbf{A}$ and $\mathbf{D}$ as examples. Although it was possible to prepare cubes Zn-1. OTf and Cd-1·OTf, as well as tetrahedra Zn-4-OTf and Cd-4·OTf, these capsules exhibited poor stability in aqueous solution (Fig. S26-S32 $\dagger$ ). Exchange of triflate for sulfate generated precipitates that we inferred to consist of cage sulfate salts. However, dissolution of $\mathbf{Z n - 1} \cdot \mathbf{S O}_{\mathbf{4}}$ and $\mathbf{C d - 1} \cdot \mathbf{S O}_{\mathbf{4}}$ in $\mathrm{D}_{2} \mathrm{O}$ resulted in rapid precipitation of subcomponent $\mathbf{A}$. While it was possible to observe low-intensity resonances attributable to cube $\mathbf{Z n - 1}$ within the first hour of dissolution, the Cd-1 framework had nearly fully hydrolysed after $10 \mathrm{~min}$. Consequently, it was not possible to recover the triflate cubes through reverse ion 


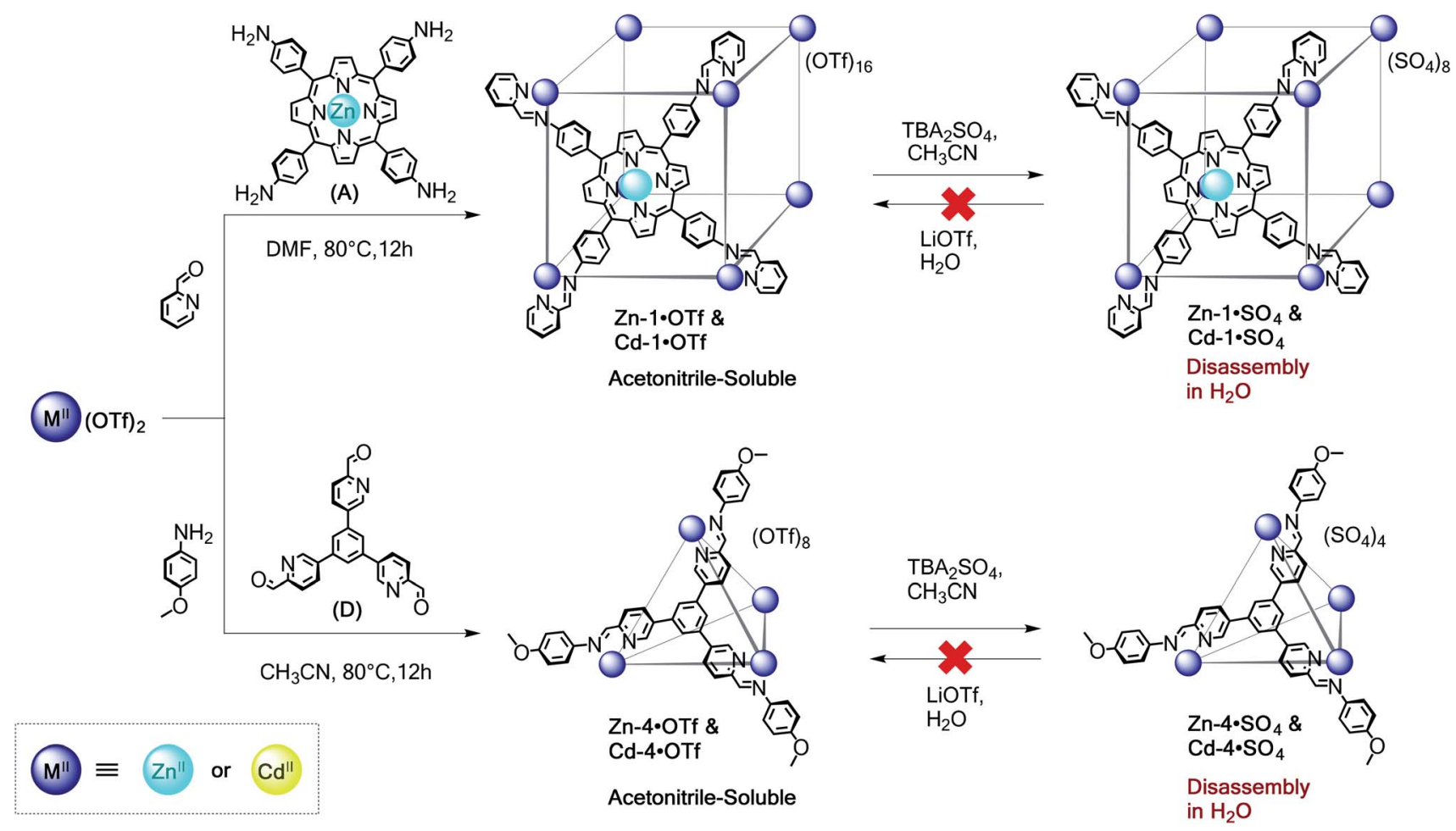

Scheme 4 Self-assembly of face-capped cubic 1 and tetrahedral 4 architectures based on zinc(॥) and cadmium(॥). Sulfate salts of capsules obtained via anion exchange from the triflate congeners were observed to disassemble in water. Direct assembly reactions using $\mathrm{ZnSO}_{4}$ or $\mathrm{CdSO}_{4}$ did not form the target water-soluble products.

exchange. Attempts to form these capsules through direct assembly from $\mathrm{ZnSO}_{4}$ or $\mathrm{CdSO}_{4}$ were unsuccessful.

\section{Water stability of $\mathrm{Zn}^{\mathrm{II}}$ and $\mathrm{Cd}^{\mathrm{II}}$ structures through increased chelate effect}

In order to prepare water-stable structures containing the more labile $\mathrm{Zn}^{\mathrm{II}}$ and $\mathrm{Cd}^{\mathrm{II}}$ template ions, we employed the chelate effect. $^{32}$ Chelating tris(2-aminoethyl)amine (TREN) and tris(3aminopropyl)amine (TRPN) subcomponents were combined with the ditopic and tritopic subcomponents. This strategy proved fruitful, resulting in the isolation of a collection of watersoluble structures as their sulfate salts; remarkably, they represent the first water-soluble subcomponent self-assembled structures containing labile $\mathrm{Zn}^{\mathrm{II}}$ and $\mathrm{Cd}^{\mathrm{II}}$ ions. Future work will probe the effects of $\mathrm{pH}$ upon the aqueous stability and guest binding properties of these assemblies.

As shown in Fig. 3, ditopic aldehydes $\mathbf{E}-\mathbf{H}$ produced $\mathrm{Zn}_{2}^{\mathrm{II}} \mathrm{L}_{3}$ triple helicates when treated with TREN and $\mathrm{ZnSO}_{4}$, whereas with TRPN and $\mathrm{CdSO}_{4}$ generated $\mathrm{Cd}_{4}^{\mathrm{II}} \mathrm{L}_{6}$ tetrahedral cages as the sole discrete products. This behaviour parallels what had been observed in the cases of Zn-6.OTf and cage Cd-11.OTf, which were previously obtained only as water-insoluble triflate salts. ${ }^{33}$

All structures were characterised by NMR spectroscopy, ESIMS, and in some cases X-ray crystallography (ESI Section $5 \dagger$ ). ESI-MS analyses showed charge states consistent with $\mathrm{Zn}_{2}^{\mathrm{II}} \mathrm{L}_{3}$ or $\mathrm{Cd}_{4}^{\mathrm{II}} \mathrm{L}_{6}$ formulations in all cases. DOSY ${ }^{1} \mathrm{H}$ NMR spectra were also consistent with the assigned structures. While the measured diffusion coefficients $(D)$ for the $\mathrm{Zn}_{2}^{\mathrm{II}} \mathrm{L}_{3}$ helicates ranged from $2.98-2.54 \times 10^{-10} \mathrm{~m}^{2} \mathrm{~s}^{-1}$, the smaller values for the $\mathrm{Cd}_{4}^{\mathrm{II}} \mathrm{L}_{6}$ tetrahedra $\left(D=2.13-1.67 \times 10^{-10} \mathrm{~m}^{2} \mathrm{~s}^{-1}\right)$ attested to their larger dimensions.

Strikingly, assembly products remained intact in solution at concentrations ranging from 100-2500 $\mu \mathrm{M}$ for more than four months at room temperature, and no decomposition was observed by NMR spectroscopy when heating their $\mathrm{D}_{2} \mathrm{O}$ solutions to $80{ }^{\circ} \mathrm{C}$. All underwent anion metathesis with LiOTf to produce the corresponding acetonitrile-soluble complexes without decomposition. The chelate effect is inferred to be responsible for the high stability of these cryptate-like structures, ${ }^{34}$ contrasting with the decomposition observed for $\mathrm{Zn}^{\mathrm{II}}$ and $\mathrm{Cd}^{\mathrm{II}}$-templated structures that do not incorporate chelating amines (Scheme 4).

Crystals of the products of subcomponent self-assembly involving aldehyde $\mathbf{F}$, helical $\mathbf{Z n - 7}$ and tetrahedral Cd-12, were grown by diffusion of ${ }^{\mathrm{i}} \mathrm{Pr}_{2} \mathrm{O}$ into $\mathrm{MeCN}$ solutions of the corresponding triflate derivatives obtained by anion metathesis with LiOTf (Fig. 3b and c). While $\mathbf{Z n - 7}$ crystallised in the monoclinic space group $C 2$ and displays a $\mathrm{Zn}_{2}^{\mathrm{II}} \mathrm{L}_{3}$ structure, $\mathrm{Cd}_{4}^{\mathrm{II}} \mathrm{L}_{6}$ assembly Cd-12 has a tetrahedral framework.

The reaction of $\mathbf{F}$ with TRPN and $\mathrm{CdSO}_{4}$ to prepare Cd$\mathbf{1 2} \cdot \mathbf{S O}_{4}$ displayed concentration dependence (Fig. S45 $\dagger$ ). When carried out at $[\mathbf{F}]=17.6 \mathrm{mM}$, two products were observed by NMR spectroscopy in a $35: 65$ ratio, consistent with $\mathrm{Cd}_{4}^{\mathrm{II}} \mathrm{L}_{6}$ cage Cd-12 $\cdot \mathbf{S O}_{4}$ and $\mathrm{a} \mathrm{Cd}_{2}^{\mathrm{II}} \mathrm{L}_{3}$ helicate. Cage formation was not suppressed by increasing the reactant concentration to $[\mathbf{F}]=$ 25.7 mM, and no interconversion between helicate and cage was 


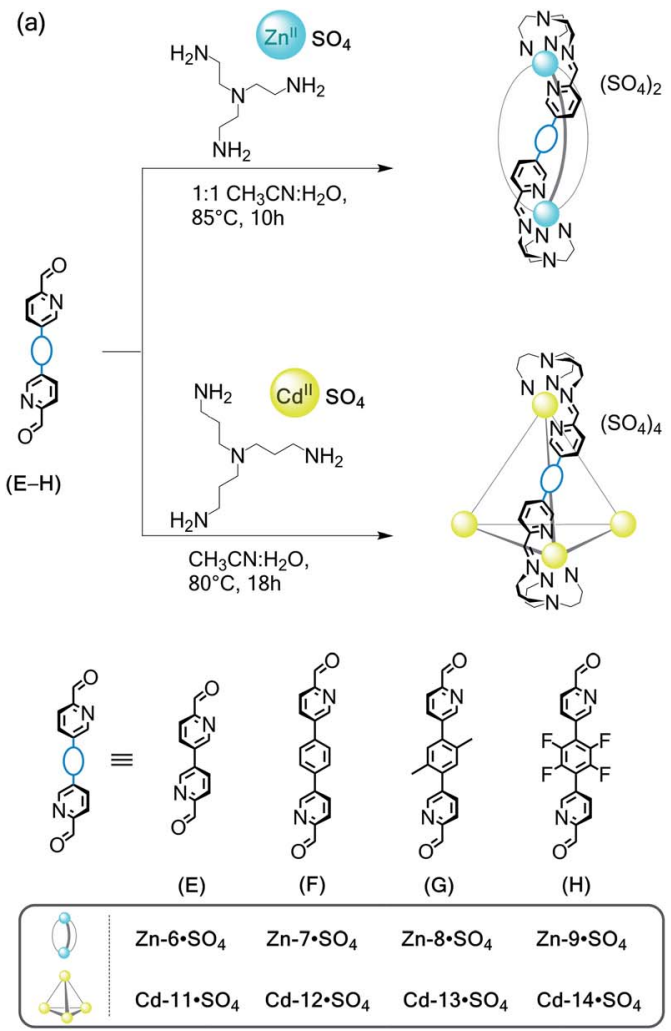

(b)

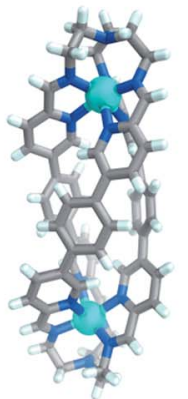

(c)

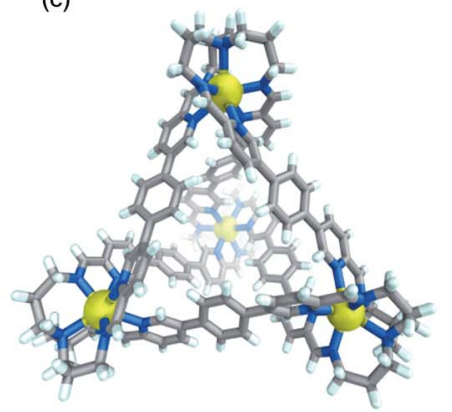

(d)

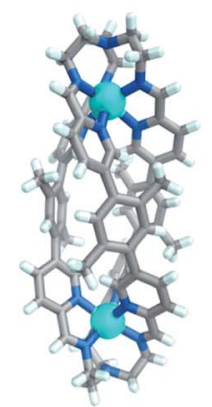

(e)

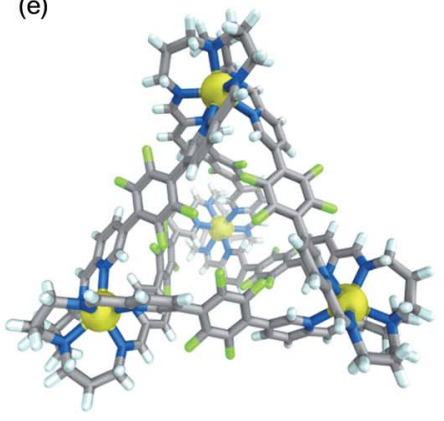

Fig. 3 Water-soluble $\mathrm{Zn}^{\prime \prime}$ - and Cd"-based architectures. (a) Self-assembly reactions to generate $\mathrm{Zn}^{\prime \prime}$-helicates and Cd"-tetrahedra from $C_{2}$ symmetric subcomponents $\mathrm{E}-\mathrm{H}$ and the tritopic amines TREN and TRPN. Structures based upon aldehyde F: cationic portions of the X-ray structures of (b) helicate Zn-7.OTf and (c) tetrahedron Cd-12.OTf. (d) Cationic parts of the X-ray structures of helicate Zn-8.OTf (based upon aldehyde G) and (e) tetrahedron Cd-14.OTf (based upon aldehyde H). Counterions, solvents and disorder are omitted for clarity. Zn", Cd" and fluorine atoms are coloured cyan, yellow, and pale green, respectively.

observed after heating the mixture to $50{ }^{\circ} \mathrm{C}$ for seven days. This observation suggested that, once formed, both products were kinetically stable with a high activation barrier preventing interconversion. When the same reaction was carried out at the lower concentration of $[\mathbf{F}]=5.7 \mathrm{mM}$, the helicate was suppressed below the limits of NMR spectroscopy detection and quantitative tetrahedron formation was observed. There is minimal steric clash between the phenylene moieties of $\mathbf{F}$ within a $\mathrm{Cd}_{2}^{\mathrm{II}} \mathrm{L}_{3}$ helicate, which we infer to lower the activation enthalpy penalty incurred by steric crowding and structural strain to a point where it matches the activation entropy penalty incurred by incorporating twice as many building blocks, to generate the Cd-12 tetrahedron. This behaviour was only observed for $\mathbf{F}$, with concentration having no perceptible effect on the outcome of self-assembly reactions involving $\mathbf{E}, \mathbf{G}$ or $\mathbf{H}$, which led to a single helicate or tetrahedron product in each case.

For dialdehydes E-H, however, when $\mathrm{CdSO}_{4}$ was used with TREN, or when $\mathrm{ZnSO}_{4}$ was used with TRPN, mixtures of soluble products with complex NMR and ESI mass spectra were observed, along with insoluble products; signals corresponding to $\mathrm{M}_{2}^{\mathrm{II}} \mathrm{L}_{3}$ helicates and $\mathrm{M}_{4}^{\mathrm{II}} \mathrm{L}_{6}$ tetrahedra were not identified. We infer that the incorporation of TRPN into a cadmium vertex leads to a geometry favourable to the formation of a $\mathrm{Cd}_{4}^{\mathrm{II}} \mathrm{L}_{6}$ tetrahedron, as the coordination of the apical nitrogen to $\mathrm{Cd}^{\mathrm{II}}$ (Fig. 3c) acts to cantilever the dialdehyde residues out into a splayed configuration that favours tetrahedron formation over the helicate. Conversely, the tighter wrapping of a TREN residue around the smaller $\mathrm{Zn}^{\mathrm{II}}$ ion, involving no apical coordination (Fig. 3b), appears to preorganise the system for helicate formation by bringing the dialdehyde residues together.

An X-ray-quality crystal of helicate Zn-8 was grown from vapour diffusion of ${ }^{\mathrm{i}} \mathrm{Pr}_{2} \mathrm{O}$ into an MeCN solution of $\mathbf{Z n - 8}$. OTf (obtained by anion metathesis with LiOTf) in the presence of excess $\mathrm{KSbF}_{6}$. Diffraction analysis of complex Zn-8 (Fig. 3d) evidenced its helical structure, with the required bending of its G moieties distributed across the three aromatic rings of each residue, as with $\mathbf{Z n - 7}$.

We recently reported that in contrast to the nonfluorinated ligand $\mathbf{F}$, the perfluorinated subcomponent $\mathbf{H}$ preferentially adopted meridional (mer) over facial ( $f a c$ ) stereochemistry around hexacoordinated $\mathrm{Fe}^{\mathrm{II}}$ ions, leading to the creation of large supramolecular prisms instead of helical or tetrahedral arrays. ${ }^{35}$ In contrast, the self-assembly of $\mathbf{H}$ with the $\mathrm{Zn}^{\mathrm{II}} / \mathrm{TREN}$ or the $\mathrm{Cd}^{\mathrm{II}} / \mathrm{TRPN}$ systems resulted in formation of helicate $\mathbf{Z n}$ 9. $\mathbf{S O}_{4}$ or tetrahedron $\mathbf{C d - 1 4} \cdot \mathbf{S O}_{4}$ as the sole observed products, respectively. ESI-MS and NMR analyses reflected the anticipated solution structures. Their simple ${ }^{1} \mathrm{H}$ NMR spectra, with one set 
of ligand resonances, are consistent with the formation of the fac coordination products; the ${ }^{19} \mathrm{~F}$ NMR spectra showed only one sharp signal for the perfluorinated phenyl ring in each case.

Treatment of an aqueous solution of $\mathbf{C d - 1 4} \cdot \mathbf{S O}_{\mathbf{4}}$ with LiOTf induced precipitation of the acetonitrile-soluble Cd-14 $\cdot$ OTf salt. ESI-MS and ${ }^{1} \mathrm{H}$ NMR analyses indicated that this structure remained intact upon anion exchange (Fig. S68 and S69†). Slow vapour diffusion of $\mathrm{Et}_{2} \mathrm{O}$ into an acetonitrile solution of Cd14. OTf containing $\mathrm{KSbF}_{6}$ allowed formation of suitable crystals for X-ray diffraction studies; Cd-14 structure crystallised in the cubic space group $P 2{ }_{1} 3$ (Fig. $3 \mathrm{e}$ ).

The use of tritopic aldehyde $\mathbf{D}$ precluded $\mathrm{Zn}$-TREN vertices from generating a helicate: the threefold connectivity of $\mathbf{D}$ requires the formation of a higher-nuclearity framework. The simplest structure possible is thus tetrahedral $\mathbf{Z n - 1 0} \cdot \mathbf{S O}_{4}$ (Scheme 5), which was the only product observed following the reaction of TREN, D and $\mathrm{ZnSO}_{4}$. The analogous $\mathbf{C d - 1 5} \cdot \mathbf{S O}_{4}$ capsule (Scheme 5) was also observed to form from TRPN, D and $\mathrm{CdSO}_{4}$.

NMR and ESI-MS analyses in water of $\mathbf{Z n - 1 0} \cdot \mathbf{S O}_{4}$ and Cd15. $\mathbf{S O}_{4}$ reflected their $T$-symmetric $\mathrm{M}_{4}^{\mathrm{II}} \mathrm{L}_{4}$ cage compositions (Fig. S70-S78†). ${ }^{1} \mathrm{H}$ NMR showed only one set of ligand resonances for each assembly. DOSY measurements were consistent with species of comparable sizes to those observed for cages Cd$\mathbf{1 1} \cdot \mathrm{SO}_{4}$ to $\mathbf{C d - 1 4} \cdot \mathrm{SO}_{4}$. These structures are stable for months at room temperature, but decomposition was observed after heating the cage $\mathrm{D}_{2} \mathrm{O}$ solutions above $80{ }^{\circ} \mathrm{C}$. Anion exchange with LiOTf rendered these tetrahedra soluble in acetonitrile but water-insoluble (Fig. S78†). We have recently reported the crystal structure of $\mathbf{Z n - 1 0} \cdot \mathbf{N T f}_{\mathbf{2}}$, obtained as the water-insoluble triflimide salt, as part of a separate study. ${ }^{36}$ Its analytical data track with those obtained in the case of $\mathbf{Z n - 1 0 \cdot O T f}$ prepared from the water-soluble sulfate salt.

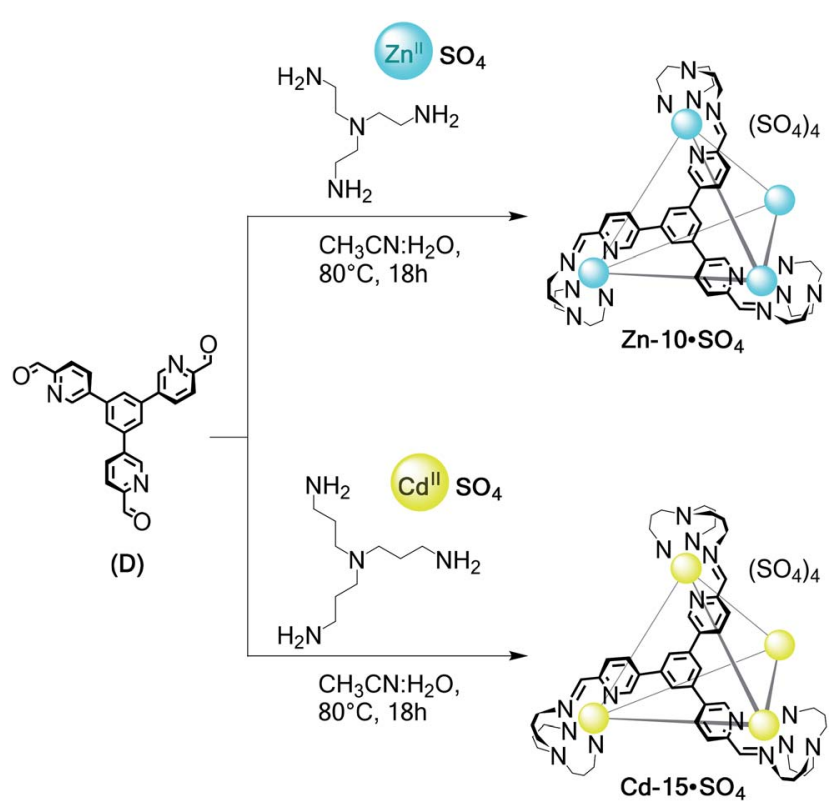

Scheme 5 Self-assembly of water-soluble $\mathrm{Zn}-10 \cdot \mathrm{SO}_{4}$ and $\mathrm{Cd}$ $15 \cdot \mathrm{SO}_{4}$ from tritopic subcomponent $\mathrm{D}$.
Factors governing the stability of subcomponent selfassembled structures in water

The differences in behaviour observed for the architectures investigated throughout this study evidenced two principal factors associated with their kinetic stability in water: the strength of metal-ligand bonding for a given metal ion, and the density of connections between metals and ligands within a structure, considering both ligand topicity (tetratopic $>$ tritopic $>$ ditopic) and degree of chelation.

The impact of metal ions on cage stability is evident from the comparison of the half lives $\left(t_{1 / 2}\right.$ at $\left.20{ }^{\circ} \mathrm{C}\right)$ and conditions required for decomposition of the cubic structures $\mathbf{M - 1} \cdot \mathbf{S O}_{\mathbf{4}}$ in water (Fig. 4). While cubes constructed from $\mathrm{Zn}^{\mathrm{II}}$ and $\mathrm{Cd}^{\mathrm{II}}$ survived only for minutes in aqueous solution, their $\mathrm{Ni}^{\mathrm{II}}, \mathrm{Fe}^{\mathrm{II}}$, and $\mathrm{Co}^{\mathrm{II}}$ congeners remained intact for months at room temperature.

Metal ions stabilise the structures into which they are incorporated following the series $\mathrm{Ni}^{\mathrm{II}}>\mathrm{Fe}^{\mathrm{II}}>\mathrm{Co}^{\mathrm{II}}>\mathrm{Zn}^{\mathrm{II}}>\mathrm{Cd}^{\mathrm{II}}$. Our observations mirror the trends in the stability constants found for mononuclear transition metal complexes of 2,2' bipyridine and 1,10-phenanthroline. ${ }^{37}$ They are also consistent with the stabilities predicted by the Irving-Williams series, ${ }^{29}$ which gives an ordering of $\mathrm{Fe}^{\mathrm{II}}<\mathrm{Co}^{\mathrm{II}}<\mathrm{Ni}^{\mathrm{II}}>\mathrm{Zn}^{\mathrm{II}}$. The inversion of $\mathrm{Fe}^{\mathrm{II}}$ and $\mathrm{Co}^{\mathrm{II}}$ is attributed to the low-spin character of $\mathrm{Fe}^{\mathrm{II}}$ in our structures, whereas high-spin $\mathrm{Fe}^{\mathrm{II}}$, which forms weaker metal-ligand bonds, ${ }^{38}$ was considered in the original Irving-

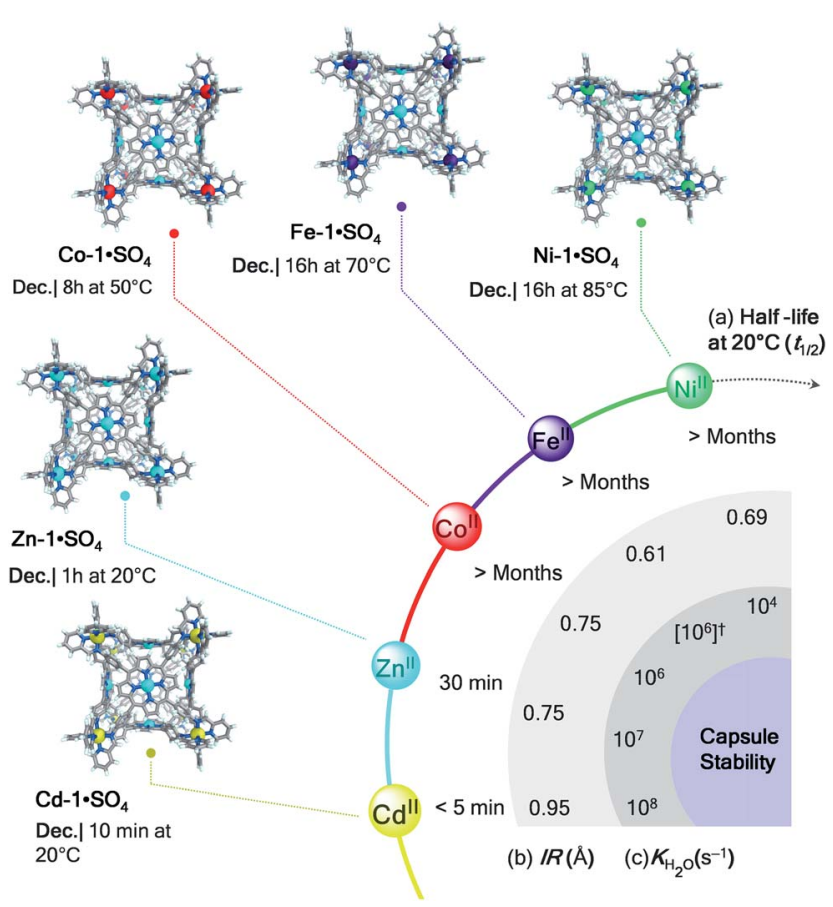

Fig. 4 Relative stability of cubes $\mathrm{M}-1 \cdot \mathrm{SO}_{4}$ in water. Crystal structures (Ni-1, Fe-1, ${ }^{22}$ and Co-1) and MM3 models (Zn-1 and Cd-1) of cubes with their decomposition conditions. (a) Half lives $\left(t_{1 / 2}\right.$ at $\left.20{ }^{\circ} \mathrm{C}\right)$, (b)

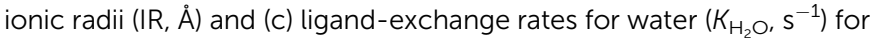
the different metal ions are displayed for comparison. (†) Although $\mathrm{Fe}-$ 1 is low-spin, $K_{\mathrm{H}_{2} \mathrm{O}}$ for high-spin $\mathrm{Fe}^{\| l}$ is given because $\left[\mathrm{Fe}\left(\mathrm{H}_{2} \mathrm{O}\right)_{6}\right]^{2+}$ is high-spin. ${ }^{19}$ 
Williams series. These results collectively suggest that the ability of each metal to hold a supramolecular structure together may be gauged by examining the ionic radius (IR, $\AA)^{39}$ and, the ligand-exchange rate of aqua ligands $\left(K_{\mathrm{H}_{2} \mathrm{O}}, \mathrm{s}^{-1}\right),{ }^{19}$ and the relative energies of the metal-ligand bonds (Fig. 4). Slower exchange rates correlate well with capsule stabilities, as do shorter radii.

Whereas $\mathrm{Fe}^{\mathrm{II}}$ (ref. 18) and $\mathrm{Co}^{\mathrm{II}}$ sulfate cages were only accessible through anion metathesis and exhibited limited stability in water, the ability of $\mathrm{Ni}^{\mathrm{II}}$ to generate the most stable structures is reflected in the formation of $\mathbf{N i - 2} \cdot \mathbf{S O}_{4}, \mathbf{N i - 3} \cdot \mathbf{S O}_{4}$, and $\mathbf{N i}-\mathbf{4} \cdot \mathbf{S O}_{4}$ directly from $\mathrm{NiSO}_{4}$ in aqueous media. Cube Ni$\mathbf{1} \cdot \mathbf{S O}_{\mathbf{4}}$ also tolerated the highest temperature among the cube series before decomposing in water (Fig. 4).

Although $\mathrm{Ni}^{\mathrm{II}}$ is known to form thermodynamically stable supramolecular ${ }^{\mathbf{4 0}}$ and mononuclear ${ }^{\mathbf{4 1}}$ complexes with chelating ligands such as 2,2'-bipyridine, $\mathrm{Ni}^{\mathrm{II}}$ structures 1-4 may not be considered thermodynamically stable in water because their decomposition was observed when their aqueous solutions were heated $\left(\mathbf{N i - 1} \cdot \mathbf{S O}_{4}\right.$ at $85{ }^{\circ} \mathrm{C}, \mathbf{N i}-\mathbf{2} \cdot \mathbf{S O}_{4}$ at $75{ }^{\circ} \mathrm{C}, \mathbf{N i}-3 \cdot \mathbf{S O}_{4}$ at $60{ }^{\circ} \mathrm{C}$, and Ni-4 $\cdot \mathrm{SO}_{4}$ at $75{ }^{\circ} \mathrm{C}$; Fig. 4 ) as evidenced by precipitation of water-insoluble subcomponents. We infer that the poor aqueous solubility of the subcomponents limits the reversibility of the dynamic covalent imine bonds and consequently the thermodynamic stability of the $\mathrm{Ni}^{\mathrm{II}}$ assemblies.

An increase in aqueous stability as ligand topicity increases also emerges clearly from our study. The tetratopic ligands of $\mathbf{1}$ lend this cubic framework the greatest degree of stability as temperatures increase, and across the widest range of metal ions. Similarly, the tritopic ligands of tetrahedra 2 and 4 led to stability with a wider range of metal ions than was observed in the cases of their congeners 3 and 5, which incorporated ditopic ligands.

We infer the topicity effect upon stability to result from the higher degree of binding cooperativity ${ }^{20}$ imposed by these ligands. Dissociation of a single ligand arm from a tetratopic ligand of 1 would require three more arms to disengage in order to free the ligand to precipitate. In contrast, dissociation of one end of a ditopic ligand of 3 would only require the other end to come off for the ligand to be free. At room temperature, framework 3 thus disintegrated in water when prepared with $\mathrm{Fe}^{\mathrm{II}}$ (ref. 18) and $\mathrm{Co}^{\mathrm{II}} ; \mathbf{3}$ was only stable in water when prepared with the most strongly binding metal, $\mathrm{Ni}^{\mathrm{II}} \cdot{ }^{37,41}$

Cooperativity $^{20}$ also plays a key role in the aqueous stabilisation of cryptate-like structures 6-15 (Fig. 3 and Scheme 5). These incorporate the most labile metals, $\mathrm{Zn}^{\mathrm{II}}$ and $\mathrm{Cd}^{\mathrm{II}}$, requiring the chelation imposed by TREN or TRPN. These dynamic cages must undergo imine hydrolysis steps in addition to delegation in order for their building blocks to become free to precipitate. A cage framework containing a single "defect", a free TREN or TRPN amine arm in proximity to an aldehyde would thus experience a high effective molarity ${ }^{20}$ for imine condensation, whereas decomposition would require the two remaining imine arms to hydrolyse. We infer the tightly-knit, cooperative construction of these cages thus to underpin their aqueous stability. Our work thus points the way to the possible preparation of even more robust water-soluble cages through the use of more coordinativelyinert $\mathrm{Ni}^{\mathrm{II}}$ or $\mathrm{Fe}^{\mathrm{II}}$ to template ${ }^{42}$ the formation of cages containing TREN and TRPN vertices.

\section{Conclusions}

This study has demonstrated the versatility of the subcomponent self-assembly method in preparing a wide range of water-soluble and kinetically stable metal-organic architectures built from hydrophobic ligands, octahedral metal ions and sulfate counter anions. $\mathrm{M}_{8}^{\mathrm{II}} \mathrm{L}_{6}$ cubes, face-capped $\mathrm{M}_{4}^{\mathrm{II}} \mathrm{L}_{4}$ tetrahedra, edge-linked $\mathrm{M}_{4}^{\mathrm{II}} \mathrm{L}_{6}$ tetrahedra as well as $\mathrm{M}_{2}^{\mathrm{II}} \mathrm{L}_{3}$ triple helicates were obtained despite the hydrophobicity and minimal aqueous solubility of their organic subcomponents.

These results may stimulate investigations involving the use of hydrophobic building blocks, which might not have been considered for use in aqueous solution, but the utility of which have been demonstrated herein. Such subcomponents show great promise for generating water-soluble architectures, when their assemblies are highly charged and paired with hydrophilic counterions.

The synthetic strategies developed herein provide a blueprint for the preparation of more intricate water-resistant metallosupramolecular structures, by employing the known concepts of using relatively inert metals and chelate cooperativity. Our implementation here takes advantage of the virtues of the subcomponent self-assembly method. Kinetic intermediates that may form at initial reaction stages were not trapped, allowing self-repair via rearrangement at the dynamic imine functions while maintaining a degree of structural integrity. We were thus able to prepare new classes of metal-organic capsules that had not previously been obtained as soluble and kinetically stable in aqueous solution.

Our study thus provides several means to control the lifetimes of capsules for prospective applications. Their disintegration in water under well-defined conditions may be advantageous for controlled drug delivery or cargo transport. ${ }^{43}$ For instance, $\mathrm{Zn}^{\mathrm{II}}$-, $\mathrm{Fe}^{\mathrm{II}}$-, $\mathrm{Co}^{\mathrm{II}}$-, and $\mathrm{Ni}^{\mathrm{II}}$-based cubes could be loaded with different cargoes, which can be released as the cages sequentially disassemble as the temperature is progressively increased. The cage components could be recovered and extracted for reassembly, as was demonstrated recently using a simple system involving a single capsule. ${ }^{\mathbf{1 0 a}}$ We also anticipate the spectroscopic properties of the cubic capsules to be of interest in aqueous solution. These properties will be investigated in due course, in the context of aqueous luminescent sensing. Other applications, such as confined-space catalysis, thermal protection of reactive chemicals or guest transport could also be built upon the waterproof architectures accessible through the approaches developed herein.

\section{Conflicts of interest}

There are no conflicts to declare. 


\section{Acknowledgements}

This research was supported by the European Research Council (695009) and the UK Engineering and Physical Sciences Research Council (EPSRC, EP/P027067/1). The authors thank the Diamond Light Source (UK) for synchrotron beamtime on I19 (MT15768) and the Cambridge University Chemistry NMR facility for performing some NMR experiments. E. G. P. acknowledges CONACYT-México for postdoctoral support. J. M. acknowledges postdoctoral fellowship support from Fundación Ramón Areces. A. J. P. acknowledges the Cambridge Trust (Vice Chancellor's Award). M. K. acknowledges the European Union's Horizon 2020 research and innovation programme under the Marie Skłodowska-Curie grant agreement No 642192.

\section{Notes and references}

1 (a) M. J. Wiester, P. A. Ulmann and C. A. Mirkin, Angew. Chem., Int. Ed., 2011, 50, 114; (b) T. R. Cook and P. J. Stang, Chem. Rev., 2015, 115, 7001; (c) Q. Zhang and K. Tiefenbacher, Nat. Chem., 2015, 7, 197.

2 (a) P. Mal, B. Breiner, K. Rissanen and J. R. Nitschke, Science, 2009, 324, 1697; (b) V. M. Dong, D. Fiedler, B. Carl, R. G. Bergman and K. N. Raymond, J. Am. Chem. Soc., 2006, 128, 14464; (c) M. Yamashina, Y. Sei, M. Akita and M. Yoshizawa, Nat. Commun., 2014, 5, 4662; (d) T. Sawada, M. Yoshizawa, S. Sato and M. Fujita, Nat. Chem., 2009, 1, 53; (e) Z. J. Wang, K. N. Clary, R. G. Bergman, K. N. Raymond and F. D. Toste, Nat. Chem., 2013, 5, 100.

3 (a) W. Cullen, M. C. Misuraca, C. A. Hunter, N. H. Williams and M. D. Ward, Nat. Chem., 2016, 8, 231; (b) C. J. Brown, F. D. Toste, R. G. Bergman and K. N. Raymond, Chem. Rev., 2015, 115, 3012; (c) C. J. Brown, R. G. Bergman and K. N. Raymond, J. Am. Chem. Soc., 2009, 131, 17530; (d) L. Catti, Q. Zhang and K. Tiefenbacher, Chem.-Eur. J., 2016, 22, 9060.

4 (a) M. Yoshizawa, M. Tamura and M. Fujita, Science, 2006, 312, 251; (b) L. Shen, N. Cao, L. Tong, X. Zhang, G. Wu, T. Jiao, Q. Yin, J. Zhu, Y. Pan and H. Li, Angew. Chem., Int. Ed., 2018, 57, 16486.

5 (a) M. Whitehead, S. Turega, A. Stephenson, C. A. Hunter and M. D. Ward, Chem. Sci., 2013, 4, 2744; (b) S. M. Biros, R. G. Bergman and K. N. Raymond, J. Am. Chem. Soc., 2007, 129, 12094; (c) M. Yamashina, M. Akita, T. Hasegawa, S. Hayashi and M. Yoshizawa, Sci. Adv., 2017, 3, e1701126; (d) C. L. D. Gibb and B. C. Gibb, J. Am. Chem. Soc., 2004, 126, 11408; (e) E. Krieg, M. M. C. Bastings, P. Besenius and B. Rybtchinsky, Chem. Rev., 2016, 116, 2414; $(f)$ F. Biedermann, M. N. Werner and H.-J. Schneider, Angew. Chem., Int. Ed., 2013, 53, 11158; (g) S. M. Biros and J. Rebek, Chem. Soc. Rev., 2007, 36, 93.

6 (a) P. S. Cremer, A. H. Flood, B. C. Gibb and D. L. Mobley, Nat. Chem., 2018, 10, 8; (b) P. Howlader, B. Mondal, P. C. Purba, E. Zangrando and P. S. Mukherjee, J. Am. Chem. Soc., 2018, 140, 7952; (c) J.-R. Li and H.-C. Zhou, Nat. Chem., 2010, 2, 893; (d) K. Ono, J. K. Klosterman, M. Yoshizawa, K. Sekiguchi, T. Tahara and M. Fujita, J. Am.
Chem. Soc., 2009, 131, 12526; (e) B. Roy, A. K. Ghosh, S. Srivastava, P. D'Silva and P. S. Mukherjee, J. Am. Chem. Soc., 2015, 137, 11916; (f) F. Schmitt, J. Freudenreich, N. P. E. Barry, L. Juillerat-Jeanneret, G. Süss-Fink and B. Therrien, J. Am. Chem. Soc., 2012, 134, 754.

7 L. Taylor, I. Riddell and M. M. J. Smulders, Angew. Chem., Int. Ed., 2018, DOI: 10.1002/anie.201806297.

8 (a) G. Liu, Y. D. Yuan, J. Wang, Y. Cheng, S. B. Peh, Y. Wang, Y. Qian, J. Dong, D. Yuan and D. Zhao, J. Am. Chem. Soc., 2018, 140, 6231; (b) Y.-P. He, L.-B. Yuan, G.-H. Chen, Q.-P. Lin, F. Wang, L. Zhang and J. Zhang, J. Am. Chem. Soc., 2017, 139, 16845.

9 (a) J. L. Bolliger, A. M. Belenguer and J. R. Nitschke, Angew. Chem., Int. Ed., 2013, 52, 7958; (b) M. B. Hillyer, C. L. D. Gibb, P. Sokkalingam, J. H. Jordan, S. E. Ioup and B. C. Gibb, Org. Lett., 2016, 18, 4048.

10 (a) D. Zhang, T. K. Ronson, J. Mosquera, A. Martinez and J. R. Nitschke, Angew. Chem., Int. Ed., 2018, 57, 3717; (b) K. Yazaki, S. Yoshihisa, M. Akita and M. Yoshizawa, Chem.-Eur. J., 2016, 22, 17557; (c) B. Roy, E. Zangrando and P. S. Mukherjee, Chem. Commun., 2016, 52, 4489.

11 (a) B. Therrien, G. Süss-Fink, P. Govindaswamy, A. K. Renfrew and P. J. Dyson, Angew. Chem., Int. Ed., 2008, 47, 3773; (b) N. P. E. Barry, O. Zava, P. J. Dyson and B. Therrien, Chem.-Eur. J., 2011, 17, 9669.

12 (a) F. Ibukuro, T. Kusukawa and M. Fujita, J. Am. Chem. Soc., 1998, 120, 8561; (b) Y.-R. Zheng, K. Suntharalingam, T. C. Johnstone and S. J. Lippard, Chem. Sci., 2015, 6, 1189.

13 C. R. K. Glasson, G. V. Meehan, J. K. Clegg, L. F. Lindoy, J. A. Smith, F. R. Keene and C. Motti, Chem.-Eur. J., 2008, 14, 10535.

14 (a) J. A. Thomas, Chem. Soc. Rev., 2007, 36, 856; (b) P. R. Symmers, M. J. Burke, D. P. August, P. I. T. Thomson, G. S. Nichol, M. R. Warren, C. J. Campbell and P. J. Lusby, Chem. Sci., 2015, 6, 756.

15 (a) N. Struch, C. Frömbgen, G. Schnakenburg and A. Lützen, Eur. J. Org. Chem., 2017, 4984; (b) B. Sun, S. S. Nurttila and J. N. H. Reek, Chem.-Eur. J., 2018, 24, 14693; (c) P. D. Frischmann, V. Kunz, V. Stepanenko and F. Würthner, Chem.-Eur. J., 2015, 21, 2766; (d) M. C. Young, A. M. Johnson, A. S. Gamboa and R. J. Hooley, Chem. Commun., 2013, 49, 1627; (e) P. F. Kuijpers, M. Otte, M. Dürr, I. Ivanović-Burmazović, J. N. H. Reek and B. de Bruin, ACS Catal., 2016, 6, 3106; (f) D. Luo, X.-Z. Wang, C. Yang, X.-P. Zhou and D. Li, J. Am. Chem. Soc., 2018, 140, 118; $(g)$ D. Luo, M. Li, X.-P. Zhou and D. Li, Chem.-Eur. J., 2018, 24, 7108; (h) H. Bunzen, Nonappa, E. Kalenius, S. Hietala and E. Kolehmainen, Chem.-Eur. J., 2013, 19, 12978; (i) J. Roukala, J. Zhu, C. Giri, K. Rissanen, P. Lantto and V.-V. Telkki, J. Am. Chem. Soc., 2015, 137, 2464; (j) K.-C. Sham, S.-M. Yiu and H.-L. Kwong, Inorg. Chem., 2013, 52, 5648; (k) D.-H. Ren, D. Qiu, C.-Y. Pang, Z. Li and Z.-G. Gu, Chem. Commun., 2015, 51, 788; (l) S. Yi, V. Brega, B. Captain and A. E. Kaifer, Chem. Commun., 2012, 48, 10295.

16 D. Zhang, T. K. Ronson and J. R. Nitschke, Acc. Chem. Res., 2018, 51, 2423. 
17 (a) Y. Zhang, X. Zheng, N. Cao, C. Yang and H. Li, Org. Lett., 2018, 20, 2356; (b) X.-Y. Hu, W.-S. Zhang, F. Rominger, I. Wacker, R. R. Schröder and M. Mastalerz, Chem. Commun., 2017, 53, 8616.

18 E. G. Percástegui, J. Mosquera and J. R. Nitschke, Angew. Chem., Int. Ed., 2017, 56, 9136.

19 M. Eigen, Pure Appl. Chem., 1963, 6, 97. The exchange rate constant of aqua ligands $\left(K_{\mathrm{H}_{2} \mathrm{O}}\right)$ for low-spin $\mathrm{Fe}^{\mathrm{II}}$ is not available; the $K_{\mathrm{H}_{2} \mathrm{O}}$ for high-spin $\mathrm{d}^{6} \mathrm{Fe}^{\mathrm{II}}\left(10^{6} \mathrm{~s}^{-1}\right)$ is used for approximate comparison to $K_{\mathrm{H}_{2} \mathrm{O}}$ for $\mathrm{Ni}^{\mathrm{II}}\left(10^{4} \mathrm{~s}^{-1}\right)$.

20 (a) L. K. S. von Krbek, C. S. Schalley and P. Thordarson, Chem. Soc. Rev., 2017, 46, 2622; (b) C. A. Hunter and H. L. Anderson, Angew. Chem., Int. Ed., 2009, 48, 7488.

21 (a) C. G. P. Taylor, J. R. Piper and M. D. Ward, Chem. Commun., 2016, 52, 6225; (b) H.-K. Liu, W.-Y. Sun, D.-J. Ma, K.-B. Yu and W.-X. Tang, Chem. Commun., 2000, 591; (c) S. Aoki, S. Suzuki, M. Kitamura, T. Haino, M. Shiro, M. Zulkefeli and E. Kimura, Chem.-Asian J., 2012, 7, 944.

22 W. Meng, B. Breiner, K. Rissanen, J. D. Thoburn, J. K. Clegg and J. R. Nitschke, Angew. Chem., Int. Ed., 2011, 50, 3479.

23 R. A Bilbeisi, J. K. Clegg, N. Elgrishi, X. de Hatten, M. Devillard, B. Breiner, P. Mal and J. R. Nitschke, J. Am. Chem. Soc., 2012, 134, 5110.

24 J. K. Clegg, J. Cremers, A. J. Hogben, B. Breiner, M. M. J. Smulders, J. D. Thoburn and J. R. Nitschke, Chem. Sci., 2013, 4, 68.

25 I. A. Riddell, M. M. J. Smulders, J. K. Clegg, Y. R. Hristova, B. Breiner, J. D. Thoburn and J. R. Nitschke, Nat. Chem., 2012, 4, 751.

26 (a) K. Mahata, P. D. Frischmann and F. Würthner, J. Am. Chem. Soc., 2013, 135, 15656; (b) A. M. Johnson, C. A. Wiley, M. C. Young, X. Zhang, Y. Lyon, R. R. Julian and R. J. Hooley, Angew. Chem., Int. Ed., 2015, 54, 5641; (c) J. M. Dragna, G. Pescitelli, L. Tran, V. M. Lynch, E. V. Anslyn and L. Di Bari, J. Am. Chem. Soc., 2012, 134, 4398; (d) N. Struch, J. G. Brandenburg, G. Schnakenburg, N. Wagner, J. Beck, S. Grimme and A. Lützen, Eur. J. Inorg. Chem., 2015, 5503; (e) P. M. Bogie, L. R. Holloway, Y. Lyon, N. C. Onishi, G. J. O. Beran, R. R. Julian and R. J. Hooley, Inorg. Chem., 2018, 57, 4155.

27 (a) M. J. Burke, G. S. Nichol and P. J. Lusby, J. Am. Chem. Soc., 2016, 138, 9308; (b) I. S. Tidmarsh, T. B. Faust, H. Adams, L. P. Harding, L. Russo, W. Clegg and M. D. Ward, J. Am. Chem. Soc., 2008, 130, 15167; (c) J. Ramírez, A.-M. Stadler, N. Kyritsakas and J.-M. Lehn, Chem. Commun., 2007, 237.

28 (a) A. Stephenson, S. P. Argent, T. Riis-Johannessen, I. S. Tidmarsh and M. D. Ward, J. Am. Chem. Soc., 2011, 133, 858; (b) T. K. Ronson, C. Giri, N. K. Beyeh, A. Minkkinen, F. Topić, J. J. Holstein, K. Rissanen and J. R. Nitschke, Chem.-Eur. J., 2013, 19, 3374; (c) I. A. Riddell, Y. R. Hristova, J. K. Clegg, C. S. Wood, B. Breiner and J. R. Nitschke, J. Am. Chem. Soc., 2013, 135, 2723; (d) X.-P. Zhou, Y. Wu and D. Li, J. Am. Chem. Soc., 2013, 135, 16062; (e) D. Lewing, H. Koppetz and F. E. Hahn, Inorg. Chem., 2015, 54, 7653.

29 H. Irving and R. J. P. Williams, J. Chem. Soc., 1953, 3192.
30 I. Bertini, C. Luchinat and P. Giacomo, in Current Methods in Inorganic Chemistry, Elsevier, Amsterdam, 2001, vol. 2, pp. 187-189.

31 (a) S. Lee, C.-H. Chen and A. H. Flood, Nat. Chem., 2013, 5, 704; (b) M. G. Fisher, P. A. Gale, M. E. Light and S. J. Loeb, Chem. Commun., 2008, 5695; (c) H. Y. Lee, A. Olasz, M. Pink, H. Park and D. Lee, Chem. Commun., 2011, 47, 481.

32 (a) M. Calvin and K. W. Wilson, J. Am. Chem. Soc., 1945, 67, 2003; (b) A. E. Martell, R. D. Hancock and R. Motekaitis, Coord. Chem. Rev., 1994, 133, 39; (c) A. W. Adamson, J. Am. Chem. Soc., 1953, 76, 1578.

33 J. Mosquera, S. Zarra and J. R. Nitschke, Angew. Chem., Int. Ed., 2014, 53, 1556.

34 (a) M.-P. Teulade-Fichou, J.-P. Vigneron and J.-M. Lehn, J. Chem. Soc., Perkin Trans. 2, 1996, 2169; (b) J.-M. Lehn, R. Méric, J.-P. Vigneron, I. Bkouche-Waksman and C. Pascard, J. Chem. Soc., Chem. Commun., 1991, 62; (c) R.-C. Brachvogel, F. Hampel and M. von Delius, Nat. Commun., 2015, 6, 7129.

35 M. Kieffer, B. S. Pilgrim, T. K. Ronson, D. A. Roberts, M. Aleksanyan and J. R. Nitschke, J. Am. Chem. Soc., 2016, 138, 6813.

36 A. M. Castilla, T. K. Ronson and J. R. Nitschke, J. Am. Chem. Soc., 2016, 138, 2342.

37 H. Irving and D. H. Mellor, J. Chem. Soc., 1962, 5222.

38 (a) S. Brooker, Chem. Soc. Rev., 2015, 44, 3192; (b) H. L. C. Feltham, A. S. Barltrop and S. Brooker, Coord. Chem. Rev., 2017, 344, 26.

39 R. D. Shannon, Acta Crystallogr., Sect. A: Cryst. Phys., Diffr., Theor. Gen. Crystallogr., 1976, 32, 751.

40 (a) R. Custelcean, P. V. Bonnesen, N. C. Duncan, X. Zhang, L. A. Watson, G. V. Berkel, W. B. Parson and B. P. Hay, J. Am. Chem. Soc., 2012, 134, 8525; (b) R. Custelecean, J. Bosano, P. V. Bonnesen, V. Kertesz and B. P. Hay, Angew. Chem., Int. Ed., 2009, 48, 4025.

41 For example: the association constants of $\mathrm{M}^{\mathrm{II}}$ complexes with 2,2'-bipyridine (bpy) $\left[\mathrm{M}(\mathrm{bpy})_{3}\right]^{2+}$ reflect stronger binding to $\mathrm{Ni}^{\mathrm{II}}$; $\log K$ at $25{ }^{\circ} \mathrm{C}$ for $\mathrm{Fe}^{\mathrm{II}}, \mathrm{Co}^{\mathrm{II}}, \mathrm{Ni}^{\mathrm{II}}, \mathrm{Zn}^{\mathrm{II}}$, and $\mathrm{Cd}^{\mathrm{II}}=17.2$, 16.0, 20.2, 13.2 and 10.4, respectively. From A. E. Martrell and R. M. Smith, Critical Stability Constants, vol. 5, Springer Science+Business, New York, 1982.

42 (a) P. Wei, X. Yan and F. Huang, Chem. Soc. Rev., 2015, 44, 815; (b) H. L. Ozores, M. Amorín and J. R. Granja, J. Am. Chem. Soc., 2017, 139, 776; (c) J. Winn, A. Pinczewska and S. M. Goldup, J. Am. Chem. Soc., 2013, 135, 13318; (d) W. M. Bloch, J. J. Holstein, B. Dittrich, W. Hiller and G. H. Clever, Angew. Chem., Int. Ed., 2018, 57, 5534; (e) S. Akine, M. Miyashita and T. Nabeshima, J. Am. Chem. Soc., 2017, 139, 4631; (f) H. Löw, E. Mena-Osteritz and M. von Delius, Chem. Sci., 2018, 9, 4785; $(g)$ P. A. Gale, N. Busschaert, C. J. E. Haynes, L. E. Karagiannidis and I. L. Kirby, Chem. Soc. Rev., 2014, 43, 205; (h) E. Kim, D. Kim, H. Jung, J. Lee, S. Paul, N. Selvapalam, Y. Yang, N. Lim, C. G. Park and K. Kim, Angew. Chem., Int. Ed., 2010, 49, 4405; (i) N. G. White and M. J. MacLachlan, Chem. Sci., 2015, 6, 6245; (j) N. Rodríguez-Vázquez, 
M. Amorín, I. Alfonso and J. R. Granja, Angew. Chem., Int. Ed., 2016, 55, 4504; (k) J. Yang, L. Shao, J. Yuan and F. Huang, Chem. Commun., 2016, 52, 12510; $(l)$ G. H. Clever and P. Punt, Acc. Chem. Res., 2017, 50, 2233; $(m)$ H. Li, A. C. Fahrenbach, A. Coskun, Z. Zhu, G. Barin, Y.-L. Zhao,
Y. Y. Botros, J.-P. Sauvage and J. F. Stoddart, Angew. Chem., Int. Ed., 2011, 50, 6782; (n) R. V. Mukhopadhyay, Y. Kim, J. Koo and K. Kim, Acc. Chem. Res., 2018, 51, 2730.

43 C. Bravin, E. Badetti, F. A. Scaramuzzo, G. Licini and C. Zonta, J. Am. Chem. Soc., 2017, 139, 6456. 